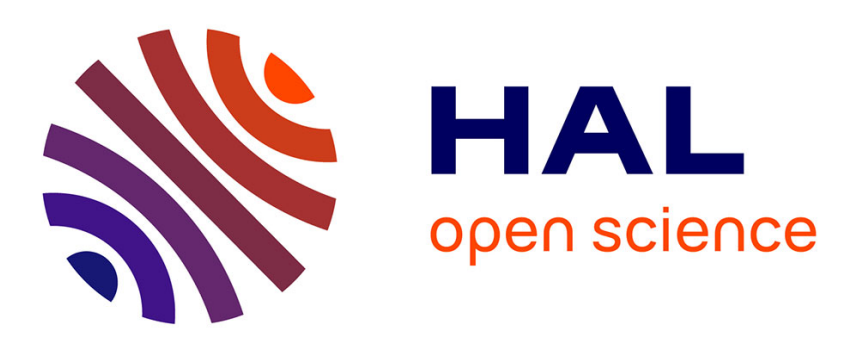

\title{
Downregulation of protein tyrosine phosphatase PTP-BL represses adipogenesis.
}

Murielle Glondu-Lassis, Mathilde Dromard, Carine Chavey, Carole Puech, Lluis Fajas, Wiljan Hendriks, Gilles Freiss

\section{- To cite this version:}

Murielle Glondu-Lassis, Mathilde Dromard, Carine Chavey, Carole Puech, Lluis Fajas, et al.. Downregulation of protein tyrosine phosphatase PTP-BL represses adipogenesis.. International Journal of Biochemistry and Cell Biology, 2009, 41 (11), pp.2173-80. 10.1016/j.biocel.2009.04.004 . inserm00422382

\section{HAL Id: inserm-00422382 https://www.hal.inserm.fr/inserm-00422382}

Submitted on 6 Oct 2009

HAL is a multi-disciplinary open access archive for the deposit and dissemination of scientific research documents, whether they are published or not. The documents may come from teaching and research institutions in France or abroad, or from public or private research centers.
L'archive ouverte pluridisciplinaire HAL, est destinée au dépôt et à la diffusion de documents scientifiques de niveau recherche, publiés ou non, émanant des établissements d'enseignement et de recherche français ou étrangers, des laboratoires publics ou privés. 
Original article

Downregulation of Protein tyrosine phosphatase

\section{PTP-BL represses adipogenesis}

Murielle Glondu-Lassis a , Mathilde Dromard ${ }^{\mathrm{a}}$, Carine Chavey ${ }^{\mathrm{a}}$, Carole Puech ${ }^{\mathrm{a}}$, Lluis Fajas ${ }^{\mathrm{a}}$, Wiljan Hendriks ${ }^{\mathrm{b}}$, and Gilles Freiss ${ }^{\mathrm{a},}$.

${ }^{\text {a }}$ IRCM, Institut de Recherche en Cancérologie de Montpellier, Montpellier, F-34298, France ; INSERM, U896, Montpellier, F-34298, France ; Université Montpellier1, Montpellier, F34298, France ; CRLC Val d'Aurelle Paul Lamarque, Montpellier, F-34298, France ; b Department of Cell Biology, Nijmegen Centre for Molecular Life Sciences, Radboud University Nijmegen Medical Centre, Nijmegen, The Netherlands.

* Corresponding author. Gilles FREISS, IRCM, Institut de Recherche en Cancérologie de Montpellier, F-34298 Montpellier cedex 5, France.

Tel: (33) (0)4 67612433

Fax: (33) (0)4 67613787

Email: gilles.freiss@valdorel.fnclcc.fr 


\begin{abstract}
The insulin / insulin-like growth factor 1 (IGF-1) signaling pathway is a major regulator of adipose tissue growth and differentiation. We recently demonstrated that human protein tyrosine phosphatase (PTP) L1, a large cytoplasmic phosphatase also known as PTP-BAS/PTPN13/PTP-1E, is a negative regulator of IGF-1R/IRS-1/Akt pathway in breast cancer cells. This triggered us to investigate the potential role of PTPL1 in adipogenesis. To evaluate the implication of PTP-BL, the mouse orthologue of PTPL1, in adipose tissue biology, we analyzed PTP-BL mRNA expression in adipose tissue in vivo and during proliferation and differentiation of 3T3-L1 pre-adipocytes. To elucidate the role of PTP-BL and of its catalytic activity during adipogenesis we use siRNA techniques in 3T3-L1 pre-adipocytes, and Mouse embryonic fibroblasts that lack wildtype PTP-BL and instead express a variant without the PTP domain $(\triangle \mathrm{P} / \Delta \mathrm{P}$ MEFs). Here we show that PTP-BL is strongly expressed in white adipose tissue and that PTP-BL transcript and protein levels increase during proliferation and differentiation of 3T3L1 pre-adipocytes. Strikingly, knockdown of PTP-BL expression in 3T3-L1 adipocytes caused a dramatic decrease in adipogenic gene expression levels $(P P A R \gamma, a P 2)$ and lipid accumulation but did not interfere with the insulin/Akt pathway. $\Delta \mathrm{P} / \Delta \mathrm{P}$ MEFs differentiate into the adipogenic lineage as efficiently as wildtype MEFs. However, when expression of either PTP-BL or PTP-BL $\triangle \mathrm{P}$ was inhibited a dramatic reduction in the number of MEF-derived adipocytes was observed. These findings demonstrate a key role for PTP-BL in 3T3-L1 and MEF-derived adipocyte differentiation that is independent of its enzymatic activity.
\end{abstract}

Key words: Protein Tyrosine Phosphatase; adipocyte differentiation; PTP-BL 


\section{Introduction}

Adipose tissue plays critical roles in the regulation of energy homeostasis; as a reservoir, by storing and releasing fuel, and as an endocrine organ, by secreting a number of hormones and cytokines (Spiegelman and Flier, 2001). Excess body fat, or obesity, is a major public health problem, particularly in industrialized countries, increasing the risk of diabetes, cardiovascular diseases and several types of cancers (Aviva Must, 1999). Conversely, lipoatrophy, the lack of adipose tissue, is also associated with diabetes and a number of other metabolic abnormalities (Spiegelman and Flier, 2001). Hence, understanding the signaling pathways that govern adipocyte differentiation is necessary to develop comprehensive therapeutic strategies for the prevention and treatment of these disorders.

Adipogenesis involves the formation of pre-adipocytes from mesenchymal progenitor cells and their differentiation into adipocytes (Rosen and Spiegelman, 2000). The cellular and molecular mechanisms of adipocyte differentiation have been extensively studied using pre-adipocyte culture systems, such as 3T3-L1 and 3T3-F442A cell lines (Rosen and Spiegelman, 2000) (Li et al., 2007). Differentiation of these cells occurs in two discrete steps. The cells first undergo several rounds of mitosis, known as clonal expansion, after which they become quiescent again and gradually acquire biochemical and morphological characteristics of mature adipocytes (Hwang et al., 1997) (Rosen and Spiegelman, 2000). Both steps are characterized by marked changes in the pattern of gene expression that are achieved by the sequential induction of transcription factors. Exposure of pre-adipocytes to appropriate hormonal inducers of adipogenesis thus results in early and transient expression of the $\beta$ and $\gamma$ isoforms of the CCAAT/enhancer-binding protein (C/EBP) (Evans et al., 2004), which contribute to the proliferation of these cells as well as to the subsequent increase in the expression of C/EBP $\alpha$ and peroxisome proliferator-activated receptor $\gamma(\operatorname{PPAR} \gamma)$ (Lane et al., 1999). The latter two proteins then mediate the activation of a variety of adipocyte-specific genes that lead to further differentiation (Hwang et al., 1997) (Lane et al., 1999).

Adipocyte differentiation is tightly regulated by insulin and IGF-1 signaling (Tseng et al., 2005). Insulin is a major hormone controlling critical energy functions, such as glucose and lipid metabolism. IGF-1 has been suggested to be a major regulator of adipose tissue growth and differentiation of preadipocytes into adipocytes. Both insulin and IGF-1 mediate adipocyte differentiation through their binding to the IGF-1 receptor (IGF-1R) (Tseng et al., 2005), which results in the induction of its 
intrinsic tyrosine kinase activity and recruitment and phosphorylation of multiple proteins including the insulin receptor substrates (IRSs). These enable the formation of macromolecular complexes close to the receptor that elicit two main signaling cascades; the phosphatidylinositol 3-kinase (PI3K) pathway and the MAPK pathway (Sanchez-Margalet et al., 1994). The MAPK pathway is considered to be involved in proliferation and differentiation, whereas the PI3K pathway plays a major role in metabolic functions, mainly via the activation of the Akt cascade. Activation of Akt stimulates glucose uptake, glycogen synthesis, protein synthesis and cell survival, and inhibits lipolysis. This pathway is also considered to be important for adipogenesis (Fasshauer et al., 2001; Sakaue et al., 1998; Xia and Serrero, 1999; Yoshiga et al., 2007).

We recently demonstrated, in human breast cancer cells, that the Protein Tyrosine Phosphatase (PTP) PTPL1 (PTPN13/PTP-BAS/PTP-1E) inhibits the IGF1-R/IRS-1/Akt pathway through dephosphorylation of IRS-1 (Dromard et al., 2007). This suggests a potential role for PTPL1 in adipogenesis. We here demonstrate that PTP-BL, the mouse ortholog of PTPL1, is strongly expressed in white adipose tissue and that PTP-BL expression levels are increased during proliferation and differentiation of mouse 3T3-L1 pre-adipocytes. Depletion of PTP-BL expression by RNAi profoundly suppressed adipocyte differentiation of 3T3-L1 and mouse embryonic fibroblast (MEF) cells. Because MEFs that lacked wildtype PTP-BL and instead expressed a truncated protein without the phosphatase domain (PTP-BL $\triangle \mathrm{P}$ ) differentiate into the adipogenic lineage as efficiently as wildtype MEFs, we conclude that PTP-BL represents a novel adipogenic factor that is required for adipocyte differentiation but that this is independent of its catalytic activity. 


\section{Materials and methods}

\section{Materials.}

All chemicals, except if stated otherwise, were purchased from Sigma (St. Louis, Missouri). Pioglitazone was a kind gift of Takeda Pharmaceuticals (Osaka, Japan). Oligofectamine reagent was purchased from Invitrogen, and Interferin from Polyplus. Anti-Akt and anti-Akt phospho-Ser473 antibodies were from Cell Signaling Technology. The antibodies against $\alpha$-tubulin and $\beta$-actin were purchased from Sigma. Anti-PTPL1 antibody (H300) was from Santa Cruz Biotechnology. Purified porcine insulin was a gift from Eli Lilly (Indianapolis, Indiana).

\section{RNA isolation; quantitative real-time PCR.}

RNA isolation was carried out using Trizol reagent according to the manufacturer instruction. Reverse transcription of total RNA was performed at $37^{\circ} \mathrm{C}$ using the M-MLV reverse transcriptase (Invitrogene SARL, France) and random hexanucleotide primers, followed by a 5 min inactivation at $95^{\circ} \mathrm{C}$. Quantitative real-time PCR was carried out using a LightCycler and the DNA double-strandspecific SYBR Green I dye for detection (Roche, Basel, Switzerland). Results were normalized to RS9 mRNA levels.

\section{Cell culture and transient transfection.}

MEFs were isolated from PTP-BL ${ }^{\Delta \mathrm{P} / \Delta \mathrm{P}}$ (Wansink et al., 2004) or wild type mice and retrovirally transduced with a TBX2 expression construct to bypass senescence (Jacobs et al., 2000). MEFs and 3T3-L1 cells were grown in DMEM, 10\% fetal bovine serum (FBS). 2 days after reaching confluence (day 0), cells were placed in differentiation media consisting of DMEM, 10\% serum, $0.5 \mathrm{mM} 3-$ Isobutyl-1methylxanthine (IBMX), $10 \mu \mathrm{g} / \mathrm{ml}$ insulin, $1 \mu \mathrm{M}$ dexamethasone, and 100nM pioglitazone for 2 days. From day 3 onwards, cells were incubated with DMEM, 10\% serum, $10 \mu \mathrm{g} / \mathrm{ml}$ insulin, and $100 \mathrm{nM}$ pioglitazone. Medium was renewed every 2 days until the end of the experiment. SiRNA transfections were carried out using the Oligofectamine reagent or Interferin methods according to the manufacturer's instructions. The PTP-BL-specific siRNA 1 (5'-G G A C C G A A U U C G A G A GA G A U U-3'), the PTPL1-specific siRNA 2 (5'-C A A A G A C G A U U C C A C U U A C U U- 
3'), and the control non-targeting siRNA from Dharmacon were used at a final concentration of $0.1 \mu \mathrm{M}$ and 2.5nM for Oligofectamine and Interferin methods, respectively.

\section{Immunoblotting analysis.}

Equal amounts of lysate were separated on an SDS/polyacrylamide gel and electrotransferred onto PVDF membrane. Blots were stained with Coomassie blue (R250, Sigma) to ensure that protein amounts were comparable. Membranes were blocked with TBST (50 mM Tris, pH 7.5, $150 \mathrm{mM} \mathrm{NaCl}$, $0.1 \%$ Tween 20) containing $5 \%$ non-fat milk and immunoblotted overnight at $4{ }^{\circ} \mathrm{C}$ with the indicated primary antibodies. Primary antibodies were detected using horseradish peroxydase-conjugated goat anti-mouse IgG or anti-rabbit IgG, along with the Western Lighting ECL detection kit (PerkinElmer Life Sciences).

Before reprobing with different primary antibodies, blots were stripped by incubation in $50 \mathrm{mM}$ Tris $\mathrm{pH} 7.5,150 \mathrm{mM} \mathrm{NaCl}, 2 \% \mathrm{SDS}$ and $100 \mathrm{mM} \beta$-mercaptoethanol, for $30 \mathrm{~min}$ at $50{ }^{\circ} \mathrm{C}$.

\section{Oil Red-O staining.}

Detection of neutral lipids with Oil Red-O was performed as described previously (Ramirez-Zacarias et al., 1992). Briefly, cells were washed twice with PBS, fixed with $4 \%$ paraformaldehyde for 30 min, and then stained for $2 \mathrm{~h}$ at room temperature with Oil Red-O solution ( $0.5 \%$ Oil Red-O in isopropanol). The cells were washed twice with PBS and visualized with an inverted microscope.

\section{BrdU incorporation.}

Cells grown on coverslips were incubated $4 \mathrm{hr}$ in the presence of $\operatorname{BrdU}(100 \mu \mathrm{M})$, and subsequently treated with $1.5 \mathrm{~N} \mathrm{HCl}$ for $10 \mathrm{~min}$ at $21^{\circ} \mathrm{C}$. After fixation and permeabilization with $100 \%$ methanol, cells were incubated with antibodies directed against BrdU (Dako A/S, Glostrup, Denmark). Preparations were then incubated with an FITC-conjugated anti-mouse IgG.

\section{Statistical analysis.}

Results are presented as mean +/- SD and the number of experiments is indicated in the figure legends. In each experiment, all determinations were performed at least in triplicate. Statistical significance was assessed using student's $t$-test. 


\section{Results}

\section{Expression pattern of PTP-BL during adipogenesis.}

To determine the relative expression of PTP-BL mRNA in vivo, we performed quantitative real-time PCR, comparing PTP-BL mRNA expression in mouse white adipose tissue with different adult mouse tissues. As previously described (Hendriks et al., 1995; Thomas et al., 1998; Wansink et al., 2004), PTP-BL gene (Ptpn13) is expressed in many epithelia and in brain (Fig. 1A). Interestingly, PTP-BL is strongly expressed in white adipose tissue from visceral and epididymal depots as compared to other tissues (Fig. 1A). Mouse 3T3-L1 pre-adipocytes are a well-characterized in vitro model of adipocyte differentiation that can reliably differentiate into mature fat cells upon exposure to differentiation media (Kehinde, 1974) (Green and Meuth, 1974). We analyzed PTP-BL mRNA and protein expression levels during proliferation of 3T3-L1 pre-adipocytes and their differentiation into mature adipocytes (Fig. 1B). Interestingly, PTP-BL expression was increased during pre-adipocyte proliferation and differentiation and peaked at confluency (day 0). This elevated expression was also observed during the differentiation process. Differentiation of the cells was verified by measuring the mRNA expression of the adipogenic markers $P P A R \gamma$ and $a P 2$ (Fig. 1C-D). Altogether, these results are in line with a role for PTP-BL in adipose tissue biology and/or differentiation.

\section{PTP-BL knockdown inhibits 3T3-L1 pre-adipocyte differentiation.}

To elucidate the role of PTP-BL during adipogenesis, we silenced PTP-BL expression using siRNA techniques. 2 days before optimal confluence, 3T3-L1 cells were transfected with two different siRNA oligonucleotides complementary to the mouse PTP-BL transcript or with an irrelevant siRNA and were compared for their ability to differentiate into adipocytes. Specific siRNA transfection resulted in a $50 \%$ inhibition of PTP-BL transcription and expression, quantified by RT-PCR (Fig.2A) and immunoblot analysis (Fig. 2B), respectively, corresponding at confluency in an expression level equal to this of proliferating pre-adipocyte. After 6 days in differentiation medium, normal lipid accumulation was observed in control cells, whereas a dramatic decrease in lipid accumulation was observed in PTP-BL knockdown cells as assessed by Oil Red O staining (Fig. 2C). By quantitative RT/PCR we detected a reduced $P P A R \gamma$ gene induction after 3 days $(30 \%)$ or 6 days $(50 \%)$ of differentiation in PTP-BL knockdown cells as compared to control cells (Fig. 2 D-E). We also 
observed a dramatically reduced induction $(80 \%)$ of the adipogenic gene marker $a P 2$ at these time points following PTP-BL knockdown (Fig. 2F-G), in line with an important role for PTP-BL in adipogenesis. We next monitored the transcript levels of the second master regulator gene, $\mathrm{C} / \mathrm{EBP} \alpha$, and two upstream regulator genes, $\mathrm{C} / \mathrm{EBP} \beta$ and $\delta$. We detected reduced $\mathrm{C} / \mathrm{EBP} \alpha$ gene induction after 4 days $(66 \%)$ or 6 days $(64 \%)$ of differentiation in PTP-BL knockdown cells as compared to control cells (Fig. $2 \mathrm{H}-\mathrm{I}$ ). However, C/EBP $\beta$ and $\delta$ transcript levels, and that of the clonal expansion associated gene c-myc, were identical in control and PTP-BL knockdown cells after 3 hours of differentiation (Fig. 2 H-I). Together, these data suggest that PTP-BL expression affects PPAR $\gamma$ and $\mathrm{C} / \mathrm{EBP} \alpha$ regulation but not through regulation of $\mathrm{C} / \mathrm{EBP} \beta$ or $\delta$ expression.

\section{Inhibition of PTP-BL impairs 3T3-L1 pre-adipocyte differentiation in the early phases without interfering with clonal expansion phase.}

Having verified that PTP-BL knock-down did not affect 3T3-L1 pre-adipocyte cell growth arrest at confluency (data not shown), we next investigated whether PTP-BL exerts its effect at the proliferative, clonal expansion phase (days 1 and 2) or rather at the differentiation stage (days 3-6) following hormonal induction of 3T3-L1 pre-adipocytes. To this end, we silenced PTP-BL expression using siRNA transfection two days before hormonal stimulation and performed BrdU incorporation studies. Consistent with our findings on the expression profiles of c-myc and the early adipogenic regulators $\mathrm{C} / \mathrm{EBP} \beta$ and $\delta, \mathrm{PTP}-\mathrm{BL}-$ silenced 3T3-L1 cells proliferated as well as control-siRNA cells (Fig. 3A), indicating that PTP-BL rather participates in stages of the 3T3-L1 differentiation process that are beyond the clonal expansion phase.

We next silenced PTP-BL gene expression at day 2 or 4 after induction of differentiation, (Fig. 3B-F), which is coincident with the completion of clonal expansion. In both cases, siRNA transfection resulted in a $50 \%$ inhibition of PTP-BL transcription as quantified by RT-PCR (Fig.3B-F). Adipocyte differentiation was also indeed inhibited upon PTP-BL knockdown 2 days after hormonal stimulation as assessed by Oil Red O staining (Fig. 3C) and $a P 2$ expression levels (Fig. 3D-E). Surprisingly, no effect was observed on the differentiation process when PTP-BL gene expression was silenced 4 days after hormonal induction (Fig. 3G-H) suggesting that PTP-BL levels are not critical for 3T3-L1 preadipocytes that have already started the differentiation process. Together, these data reveal that PTP- 
$\mathrm{BL}$ is important for the early steps of adipocyte differentiation, but not proliferation program. The upregulation of PTP-BL gene expression that occurs during the proliferation and differentiation of 3T3L1 pre-adipocytes thus appears to be essential for the initiation of the differentiation process.

\section{PTP-BL regulates adipogenesis independently of its phosphatase activity.}

Insulin/IGF-1/IRS pathway has an important role in the regulation of genes that are involved in multiple early adipogenic events in brown pre-adipocytes (Tseng et al., 2005). Activation of Akt is considered to be important for adipogenesis (Fasshauer et al., 2001; Sakaue et al., 1998; Xia and Serrero, 1999; Xu and Liao, 2004; Yoshiga et al., 2007). We have recently shown that PTPL1 expression was sufficient to modulate Akt activation in the IGF1-R/IRS-1/Akt pathway through IRS-1 dephosphorylation in breast cancer cells (Dromard et al., 2007). PTP-BL gene expression was silenced before the clonal expansion and we tested whether PTP-BL's critical contribution to the early phase of 3T3-L1 differentiation into adipocytes involves IRS-1/Akt pathway deactivation. In confluent 3T3-L1 pre-adipocytes (day 0), the level of IRS-1 tyrosine phosphorylation in response to insulin is very low compared to mature adipocyte and, in contrast to our findings in human breast cancer cells, PTP-BL knock-down has no effect on IRS-1 activation (data not shown) or insulin-induced Akt phosphorylation in 3T3-L1 cells (Fig. 4A).

Finally, we wanted to assess the participation of PTP-BL's tyrosine phosphatase activity in adipocyte differentiation. Poor transfection efficiency in 3T3-L1 pre-adipocytes prevented experiments using overexpression of PTP-BL phosphatase-dead mutant. We therefore turned to mouse embryonic fibroblast (MEF) cells that were derived from mice that lack the PTP-BL phosphatase moiety (PTP$\mathrm{BL}^{\Delta \mathrm{P} / \Delta \mathrm{P}}$ mice) (Wansink et al., 2004). The capacity of $\Delta \mathrm{P} / \Delta \mathrm{P}$ MEFs, that express an enzymatically inactive truncated version of the protein $(\mathrm{PTP}-\mathrm{BL} \Delta \mathrm{P})$, to differentiate into adipocytes in vitro in response to hormone stimulation was compared to that of wild-type (wt) MEFs. Adipocytes were scored using Oil Red O staining to detect lipid droplets and mRNA expression of adipogenic markers was quantified. Hormonally stimulated $\triangle \mathrm{P} / \Delta \mathrm{P}$ MEFs differentiated into adipocytes in vitro as efficiently as $w t$ MEFs (Fig. 4B-C), indicating that PTP-BL catalytic activity is not required for adipocyte differentiation of MEFs. However, like in 3T3-L1 cells, PTP-BL is required for MEF 
adipocyte differentiation since PTP-BL inhibition by siRNA technique in wt (data not shown) as well as $\triangle \mathrm{P} / \triangle \mathrm{P}$ MEFs caused a dramatic decrease in lipid droplets accumulation as assessed by Oil Red $\mathrm{O}$ staining (Fig. 4E). Gene expression analysis of the adipose tissue-specific genes $P P A R \gamma$ and $a P 2$ (Fig4 F-G) further corroborated this finding. Taken together, these data imply that not the catalytic activity but PTP-BL's anchoring and scaffolding functions are required for adipocyte differentiation. 


\section{Discussion}

Time-dependent modulation of intracellular signaling molecules and sequential induction of transcriptional regulators that generate marked changes in gene expression are essential for the differentiation of pre-adipocytes into adipocytes (Rangwala and Lazar, 2000) (Koutnikova and Auwerx, 2001). The transcriptional regulation of adipogenesis is relatively well characterized, with PPAR $\gamma$ and $\mathrm{C} / \mathrm{EBP} \alpha$ as two master regulators that control adipogenic genes (Nedergaard et al., 2005). However, the factors that influence pre-adipocyte determination remain poorly understood. Here we demonstrate that the mouse protein tyrosine phosphatase PTP-BL is strongly expressed in white adipose tissue and its expression levels are upregulated during proliferation and differentiation of 3T3L1 pre-adipocytes, suggesting a role for PTP-BL in adipose tissue biology. Indeed, we found that PTPBL plays a key role in 3T3-L1 adipocyte differentiation. We show that blocking the up-regulation of PTP-BL expression in the early phases of adipogenesis was associated with a dramatic decrease in adipogenic gene expression and lipid accumulation in 3T3-L1 adipocytes.

A number of diverse functions have been described to PTP-BL, given the varied proteins that it has been shown to interact with. For example, PTP-BL has been suggested to act as a scaffolding protein in the regulation of the cytoskeleton (Erdmann, 2003), to dephosphorylate EphrinB and thus regulate various developmental processes (Palmer et al., 2002), and to be involved in the regulation of cytokinesis (Herrmann et al., 2003). Reports based on the characterization of mice that lack PTP-BL phosphatase activity revealed a phenotype of impairment in motor nerve repair (Wansink et al., 2004) and the involvement of PTP-BL in both retinal ganglion cell neurite initiation and survival of activated retinal glia (Lorber et al., 2005). Recently, a published study on mutant mice that are completely devoid of PTP-BL did not report phenotypic consequences or an effect on adipogenesis and solely focalized on haematopoietic cell lineages (Nakahira et al., 2007) which were previously shown to express the phosphatase (Gjorloff-Wingren et al., 2000). For the human homologue of PTP-BL, PTPL1, a role in apoptosis has been proposed, but this is still a matter of debate and depending on Fas pathway effectiveness and PTPL1 expression level (Sato et al., 1995) (Abaan et al., 2005; Bompard et al., 2002; Cuppen et al., 2000; Miyazaki et al., 2006; Toretsky et al., 1997; Wieckowski et al., 2007). 
Our own studies have shown that PTPL1 is necessary (Bompard et al., 2002) and sufficient (Dromard et al., 2007) for the early inhibition of the IRS-1/PI3K/Akt pathway through IRS-1 dephosphorylation.

The insulin/IGF-1/IRS signaling pathway has an important role in the regulation of genes that are involved in multiple early adipogenic events in brown pre-adipocytes (Tseng et al., 2005). Activation of Akt is considered to be important for adipogenesis (Fasshauer et al., 2001; Sakaue et al., 1998; Xia and Serrero, 1999; Xu and Liao, 2004; Yoshiga et al., 2007). The Akt signal cascade appears to induce or activate PPAR $\gamma$ and C/EBP during the induction of 3T3-L1 adipocyte differentiation (Kim and Chen, 2004; Kortum et al., 2005; Lazar, 2005; Nedergaard et al., 2005). Recently, PPAR $\gamma 2$ expression was shown to be negatively regulated by Foxo-1, through binding to the PPAR $\gamma$ promoter and inhibition of transcription. (Armoni et al., 2006). Insulin induces phosphorylation and nuclear export of Foxo-1 through Akt. Therefore, the IR/IGF-1R-IRS-PI3-kinase-Akt pathway promotes PPAR $\gamma$ expression. Surprisingly, we found that PTP-BL knock-down had no apparent effect on IRS-1 tyrosine phosphorylation and Akt activation in 3T3-L1 pre-adipocytes. This may be indicative for compensatory actions from other PTPs present in these cells but may also point to a regulatory mechanism controlling PTP-BL activity as encountered during oocyte meiotic maturation (Nedachi and Conti, 2004). Still, PTP-BL was found to be required during the early phase of adipocyte differentiation that directly follows the clonal expansion phase. Interestingly, we could demonstrate that PTP-BL phosphatase activity is not required for this effect on adipocyte differentiation, in line with the absence of an effect of PTP-BL on the IRS-1/Akt pathway. Indeed, MEFs (C57BL/6) expressing a PTP-BL protein lacking its PTP domain differentiated into the adipogenic lineage as efficiently as wild type cells. This is in accordance with the fact that PTP-BL ${ }^{\Delta \mathrm{P} / \Delta \mathrm{P}}$ mice, that lack the PTP-BL catalytic domain, do not display any abnormality in adipose tissue development when bred onto a C57BL/6 genetic background (Wansink et al., 2004). In that light, it will be interesting to learn whether any adipose tissue abnormalities become apparent in the full PTP-BL knock-out mice that were recently generated (Nakahira et al., 2007).

PTP-BL and PTPL1 represent the largest mammalian intracellular PTP in mice and human, respectively, and possess at least seven potential protein-protein interaction domains; a kinase noncatalytic C-lobe (KIND) domain, a Four-point-one-Ezrin-Radixin-Moesin (FERM) domain, and 
five PSD-95-Drosophila discs large-Zonula occludens (PDZ) domains. Many potential interacting proteins have been identified (Erdmann, 2003). The contribution of PTP-BL to the adipocyte differentiation process seems to be reflected by its potency to orchestrate the composition and dynamics of large protein machines through these many protein interaction modules rather than by its enzymatic activity. The precise molecular mechanism by which PTP-BL participates in adipogenesis, however, remains to be uncovered.

Elucidation of PTP-BL's working mechanism as an adipogenic factor might result in new therapeutic strategies for the treatment of obesity that will involve the abrogation of PTP-BL protein complexes rather than inhibition of its enzymatic activity.

\section{Acknowledgments}

This work was supported by the Institut National de la Santé et de la Recherche Médicale, the Ligue Nationale Contre le Cancer Languedoc Roussillon, by Institut National du Cancer, and by the Agence Nationale de la Recherche. M. Dromard was supported by a fellowship from Ligue Nationale Contre le Cancer Langeudoc Roussillon, M. Glondu-Lassis by a post-doctoral Fellowship from Institut National du Cancer, and C. Chavey by a post-doctoral Fellowship from the Agence Nationale de la Recherche. We thank Jan Schepens, Ad de Groof and Frank Oerlemans for assisting in the isolation and immortalization of mouse embryonic fibroblast lines. 


\section{References}

Abaan OD, Levenson A, Khan O, Furth PA, Uren A and Toretsky JA. PTPL1 is a direct transcriptional target of EWS-FLI1 and modulates Ewing's Sarcoma tumorigenesis. Oncogene $2005 ; 24: 2715-22$.

Armoni M, Harel C, Karni S, Chen H, Bar-Yoseph F, Ver MR, et al. FOXO1 represses peroxisome proliferator-activated receptor-gamma1 and -gamma2 gene promoters in primary adipocytes. A novel paradigm to increase insulin sensitivity. J Biol Chem 2006; 281:19881-91.

Aviva Must PJS, MS; Eugenie H. Coakley, MA, MPH; Alison E. Field, ScD; Graham Colditz, MD, DrPH; William H. Dietz, MD, PhD. The Disease Burden Associated With Overweight and Obesity. JAMA 1999; 282:1523-9.

Bompard G, Puech C, Prebois C, Vignon F, Freiss G, Freiss G, et al. Protein-tyrosine phosphatase PTPL1/FAP-1 triggers apoptosis in human breast cancer cells Extinction of insulin-like growth factor-I mitogenic signaling by antiestrogen-stimulated Fasassociated protein tyrosine phosphatase-1 in human breast cancer cells. J Biol Chem 2002; 277:47861-9.

Cuppen E, van Ham M, Wansink DG, de Leeuw A, Wieringa B and Hendriks W. The zyxinrelated protein TRIP6 interacts with PDZ motifs in the adaptor protein RIL and the protein tyrosine phosphatase PTP-BL. Eur J Cell Biol 2000; 79:283-93.

Dromard M, Bompard G, Glondu-Lassis M, Puech C, Chalbos D and Freiss G. The putative tumor suppressor gene PTPN13/PTPL1 induces apoptosis through insulin receptor substrate-1 dephosphorylation. Cancer Res 2007; 67:6806-13.

Erdmann KS. The protein tyrosine phosphatase PTP-Basophil/Basophil-like. Interacting proteins and molecular functions. Eur J Biochem 2003; 270:4789-98.

Evans RM, Barish GD and Wang YX. PPARs and the complex journey to obesity. Nat Med 2004; 10:355-61.

Fasshauer M, Klein J, Kriauciunas KM, Ueki K, Benito M and Kahn CR. Essential role of insulin receptor substrate 1 in differentiation of brown adipocytes. Mol Cell Biol 2001; 21:319-29.

Gjorloff-Wingren A, Saxena M, Han S, Wang X, Alonso A, Renedo M, et al. Subcellular localization of intracellular protein tyrosine phosphatases in T cells. Eur J Immunol 2000; 30:2412-21.

Green $\mathrm{H}$ and Meuth M. An established pre-adipose cell line and its differentiation in culture. Cell $1974 ; 3: 127-33$.

Hendriks W, Schepens J, Bachner D, Rijss J, Zeeuwen P, Zechner U, et al. Molecular cloning of a mouse epithelial protein-tyrosine phosphatase with similarities to submembranous proteins. J Cell Biochem 1995; 59:418-30.

Herrmann L, Dittmar T and Erdmann KS. The protein tyrosine phosphatase PTP-BL associates with the midbody and is involved in the regulation of cytokinesis. Mol Biol Cell 2003; 14:23040 .

Hwang CS, Loftus TM, Mandrup S and Lane MD. Adipocyte differentiation and leptin expression. Annu Rev Cell Dev Biol 1997; 13:231-59. 
Jacobs JJ, Keblusek P, Robanus-Maandag E, Kristel P, Lingbeek M, Nederlof PM, et al. Senescence bypass screen identifies TBX2, which represses Cdkn2a (p19(ARF)) and is amplified in a subset of human breast cancers. Nat Genet 2000; 26:291-9.

Kehinde $\mathrm{HGaO}$. Sublines of mouse $3 \mathrm{~T} 3$ cells that accumulate lipid. cell 1974; Volume 1:Pages 113-6.

Kim JE and Chen J. regulation of peroxisome proliferator-activated receptor-gamma activity by mammalian target of rapamycin and amino acids in adipogenesis. Diabetes 2004; 53:2748-56.

Kortum RL, Costanzo DL, Haferbier J, Schreiner SJ, Razidlo GL, Wu MH, et al. The molecular scaffold kinase suppressor of Ras 1 (KSR1) regulates adipogenesis. Mol Cell Biol 2005; 25:7592-604.

Koutnikova H and Auwerx J. Regulation of adipocyte differentiation. Ann Med 2001; 33:556-61.

Lane MD, Tang QQ and Jiang MS. Role of the CCAAT enhancer binding proteins (C/EBPs) in adipocyte differentiation. Biochem Biophys Res Commun 1999; 266:677-83.

Lazar MA. PPAR gamma, 10 years later. Biochimie 2005; 87:9-13.

Li FQ, Singh AM, Mofunanya A, Love D, Terada N, Moon RT, et al. Chibby promotes adipocyte differentiation through inhibition of beta-catenin signaling. Mol Cell Biol 2007; 27:4347-54.

Lorber B, Hendriks WJ, Van der Zee CE, Berry M and Logan A. Effects of LAR and PTP-BL phosphatase deficiency on adult mouse retinal cells activated by lens injury. Eur J Neurosci 2005; 21:2375-83.

Miyazaki T, Atarashi Y, Yasumura S, Minatoya I, Ogawa K, Iwamoto M, et al. Fas-associated phosphatase-1 promotes Fas-mediated apoptosis in human colon cancer cells: novel function of FAP-1. J Gastroenterol Hepatol 2006; 21:84-91.

Nakahira M, Tanaka T, Robson BE, Mizgerd JP and Grusby MJ. Regulation of signal transducer and activator of transcription signaling by the tyrosine phosphatase PTP-BL. Immunity 2007; 26:163-76.

Nedachi T and Conti M. Potential role of protein tyrosine phosphatase nonreceptor type 13 in the control of oocyte meiotic maturation. Development 2004; 131:4987-98.

Nedergaard J, Petrovic N, Lindgren EM, Jacobsson A and Cannon B. PPARgamma in the control of brown adipocyte differentiation. Biochim Biophys Acta 2005; 1740:293-304.

Palmer A, Zimmer M, Erdmann KS, Eulenburg V, Porthin A, Heumann R, et al. EphrinB phosphorylation and reverse signaling: regulation by Src kinases and PTP-BL phosphatase. Mol Cell 2002; 9:725-37.

Ramirez-Zacarias JL, Castro-Munozledo F and Kuri-Harcuch W. Quantitation of adipose conversion and triglycerides by staining intracytoplasmic lipids with Oil red O. Histochemistry 1992; 97:493-7.

Rangwala SM and Lazar MA. Transcriptional control of adipogenesis. Annu Rev Nutr 2000; 20:535-59. 
Rosen ED and Spiegelman BM. Molecular regulation of adipogenesis. Annu Rev Cell Dev Biol 2000; 16:145-71.

Sakaue H, Ogawa W, Matsumoto M, Kuroda S, Takata M, Sugimoto T, et al. Posttranscriptional control of adipocyte differentiation through activation of phosphoinositide 3-kinase. J Biol Chem $1998 ; 273: 28945-52$.

Sanchez-Margalet V, Goldfine ID, Vlahos CJ and Sung CK. Role of phosphatidylinositol-3kinase in insulin receptor signaling: studies with inhibitor, LY294002. Biochem Biophys Res Commun 1994; 204:446-52.

Sato T, Irie S, Kitada S and Reed JC. FAP-1: a protein tyrosine phosphatase that associates with Fas. Science 1995; 268:411-5.

Spiegelman BM and Flier JS. Obesity and the regulation of energy balance. Cell 2001; 104:53143.

Thomas T, Voss AK and Gruss P. Distribution of a murine protein tyrosine phosphatase BL-betagalactosidase fusion protein suggests a role in neurite outgrowth. Dev Dyn 1998; 212:250-7.

Toretsky JA, Kalebic T, Blakesley V, LeRoith D and Helman LJ. The insulin-like growth factor-I receptor is required for EWS/FLI-1 transformation of fibroblasts. J Biol Chem 1997; 272:308227.

Tseng YH, Butte AJ, Kokkotou E, Yechoor VK, Taniguchi CM, Kriauciunas KM, et al. Prediction of preadipocyte differentiation by gene expression reveals role of insulin receptor substrates and necdin. Nat Cell Biol 2005; 7:601-11.

Wansink DG, Peters W, Schaafsma I, Sutmuller RP, Oerlemans F, Adema GJ, et al. Mild impairment of motor nerve repair in mice lacking PTP-BL tyrosine phosphatase activity. Physiol Genomics 2004; 19:50-60.

Wieckowski E, Atarashi Y, Stanson J, Sato TA and Whiteside TL. FAP-1-mediated activation of NF-kappaB induces resistance of head and neck cancer to Fas-induced apoptosis. J Cell Biochem 2007; 100:16-28.

Xia $\mathrm{X}$ and Serrero G. Inhibition of adipose differentiation by phosphatidylinositol 3-kinase inhibitors. J Cell Physiol 1999; 178:9-16.

$\mathrm{Xu} \mathrm{J}$ and Liao K. Protein kinase B/AKT 1 plays a pivotal role in insulin-like growth factor-1 receptor signaling induced 3T3-L1 adipocyte differentiation. J Biol Chem 2004; 279:35914-22.

Yoshiga D, Sato N, Torisu T, Mori H, Yoshida R, Nakamura S, et al. Adaptor protein SH2-B linking receptor-tyrosine kinase and Akt promotes adipocyte differentiation by regulating peroxisome proliferator-activated receptor gamma messenger ribonucleic acid levels. Mol Endocrinol 2007; 21:1120-31. 


\section{Figure legends}

Figure 1 : Expression pattern of PTP-BL during adipogenesis. (A) Relative expression of PTP-BL mRNA as determined by quantitative real-time PCR in different mouse tissues. BAT, brown adipose tissue; WAT, white adipose tissue from epididymal fat pad. Visceral, but not subcutaneous, WAT also displays high PTP-BL expression levels (data not shown). Results were normalized to the expression of RS9 mRNA and are expressed as the mean $+/-$ SD from four independent experiments. (B) Quantitative real-time PCR showing PTP-BL gene expression during proliferation of 3T3-L1 cells and at the indicated days of adipocyte differentiation. Results are expressed as a mean from two independent experiments. Insert: Western blot, representative of two independent experiments, showing the increased expression of PTP-BL protein (upper panel) during 3T3L1 proliferation and differentiation.Immunodetection of b-actin served as loading control (lower panel). (C-D) Analysis of the expression of adipocyte markers $a P 2$ and $P P A R \gamma$ just before (d0) and 6 days after initiation of 3T3-L1 adipocytes. Results are representative of two independent experiments.

Figure 2 : PTP-BL knockdown inhibits 3T3-L1 adipogenesis. Cells were transfected with siRNA (control or PTP-BL specific) two days before hormonal stimulation. (A) Quantitative real-time PCR showing PTP-BL gene expression. (B) Western blot showing knockdown of PTP-BL expression. (C) Micrographs of Oil Red O staining of PTP-BL-silenced 3T3-L1 cells (PTP-BL-siRNA1 and 2) and control (control-siRNA) after 6 days of differentiation. (D-G) Quantitative real-time PCR showing expression of the adipogenic markers PPARy (D-E) and $a P 2$ (F-G), in knockdown versus control differentiation experiments, at the indicated days of 3T3-L1 adipocyte differentiation. Results were normalized to the expression of RS9 mRNA and are expressed as a mean +/- SD from four independent experiments. ${ }^{*} \mathrm{P}<0.001$; $* * \mathrm{P}<0.0001$. (H-I) Quantitative real-time $\mathrm{PCR}$ showing expression of the adipogenic marker $C / E B P \alpha$, the upstream regulator genes $\mathrm{C} / \mathrm{EBP} \beta$ and $\mathrm{C} / \mathrm{EBP} \delta$ and the clonal expansion associated gene $c-m y c$, in PTP-BL-siRNA- versus control-siRNA-treated 3T3-L1 adipocytes, at the indicated time of differentiation. Results were normalized to RS9 mRNA levels and are expressed as a mean $+/-\mathrm{SD}$ from four $(C / E B P a)$ or two $(C / E B P \beta$ and $\delta, c-m y c)$ independent experiments. ${ }^{*} \mathrm{P}<0.04$. 


\section{Figure 3 : Inhibition of PTP-BL impairs 3T3-L1 pre-adipocyte early phase differentiation but}

not clonal expansion. (A) 3T3-L1 cells were transfected with siRNA (control or PTP-BL-specific) two days before stimulation and BrdU incorporation was quantified at the indicated days of differentiation by immunofluorescence. Results are the mean of at least 500 cells in two independent experiments. (B-E) Cells were transfected with siRNA (control or PTP-BL-specific) two days after stimulation. (B) Knockdown of PTP-BL gene expression in 3T3-L1 cells transfected with siRNA was assessed by quantitative real-time PCR. (C) Micrographs of Oil Red O staining of PTP-BL-silenced 3T3-L1 cells (PTP-BL-siRNA) and control (control-siRNA) after 6 days of differentiation. (D-E) Quantitative real-time PCR showing gene expression of the adipogenic markers $a P 2$ in knockdown versus control cells at the indicated days of 3T3-L1 adipocyte differentiation. Results were normalized to the expression of RS9 mRNA and are expressed as the mean +/- SD from four independent experiments. ${ }^{*} \mathrm{P}<0.001$. (F-H) pre-adipocytes were transfected with siRNA (control or PTP-BLspecific) four days after stimulation. (G) Micrographs of Oil Red O staining of PTP-BL-silenced 3T3L1 cells (PTP-BL-siRNA) and control (control-siRNA) after 6 days of differentiation. (H) Quantitative real-time PCR showing $a P 2$ gene expression levels in knockdown versus control cells after 6 days of differentiation. Results are expressed as the mean +/- SD from three independent experiments. ${ }^{*} \mathrm{P}<0.001$.

Figure 4 : PTP-BL regulation of adipogenesis does not require its phosphatase activity. (A) 3T3L1 cells were serum-starved for $8 \mathrm{~h}$ and were stimulated (+) or not (-) for $10 \mathrm{~min}$ with insulin at the indicated days of 3T3-L1 cells differentiation. Equal amounts of cell lysates were resolved by two separate $10 \%$ SDS-PAGE gels. One membrane was probed with anti-phosphorylated Akt (pAkt; upper panels) antibody and the other with anti-Akt antibody (middle panels) before reprobing with anti- $\beta$-actin antibody (lower panels). (B) Micrographs of Oil Red O staining of $\Delta \mathrm{P} / \Delta \mathrm{P}$ MEFs or wt MEFs 10 days after differentiation. (C) Quantitative real-time PCR showing gene expression of the adipogenic markers aP2 and PPAR $\gamma$ in $\triangle \mathrm{P} / \triangle \mathrm{P}$ MEFs or wt MEFs after 10 days of differentiation. (DE) PTP-BL $\Delta \mathrm{P}$ expression and lipid storage in $\Delta \mathrm{P} / \Delta \mathrm{P}$ MEFs cells transfected with a siRNA sequence directed against mouse PTP-BL two days before optimal confluence. (D) Cells were lysed at confluency and PTP-BL $\Delta$ P expression was evaluated by Western blot. (E) Micrographs of Oil Red O 
staining of PTP-BL-silenced $\Delta \mathrm{P} / \Delta \mathrm{P}$ MEFs (PTP-BL-siRNA) and control (control-siRNA) after 10 days of differentiation. (F-G) Quantitative real-time PCR showing gene expression of the adipogenic markers $P P A R \gamma(\mathrm{F})$ and $a P 2(\mathrm{G})$ in knockdown versus control $\triangle \mathrm{P} / \Delta \mathrm{P}$ MEFs following 10 days of differentiation. Results were normalized to the expression of RS9 mRNA and are expressed as the mean $+/$ - SD from three independent experiments. ${ }^{*} \mathrm{P}<0.001 ; * * \mathrm{P}<0.0001$. 